\title{
Risks and Reliability in a Fully Renewable Switzerland
}

\author{
S. Bartlett ${ }^{1}$, B. Kruyt ${ }^{1,2}$, A. Kahl ${ }^{1} \&$ M. Lehning ${ }^{1,2}$ \\ 1) Laboratory of Cryospheric Sciences, School of Architecture, Civil and Environmental Engineering \\ École Polytechnique Fédérale de Lausanne, Lausanne, Switzerland
}

2) WSL Institute for Snow and Avalanche Research SLF

Davos, Switzerland

\section{ABSTRACT}

Climate change, resource depletion and pollution concerns, among others, compel us to seek renewable sources of energy to power our societies. In Switzerland, the government has made ambitious plans for a major energy transition. There is a planned phase out of nuclear facilities by mid-century, their capacity replaced by an expansion of hydroelectric infrastructure, new geothermal installations, and a considerable number of new solar and wind plants. The principle challenge of this transition is the variational nature of renewable energy. Switzerland generates significantly more hydroelectric power during the snowmelt season than in mid-winter, and solar power has lower yields in the winter. Thus a $100 \%$ renewable Switzerland is a desirable goal but brings great challenges, which require specific methods of management.In this work, we carry out a first order assessment of a future Swiss energy system powered exclusively by renewable energy, and highlight the principle operational risks.

We approximate yields from the various renewable sources using meteorological data for the five year period: 2010-2014. We also use figures for national electrical load to calculate the supply/demand mis-match for the same period. When averaged spatially (with the assumption of a perfect intra-national transmission infrastructure), but resolved in time, we find there is a significant seasonal variation (see Figure 1(a)).

Averaging in time, but assuming only local electrical transmission reveals a second issue: The southern part of the country has a net energy surplus, whereas the central plateau exhibits a large deficit (see Figure 1(b)). This is due to the large generation capacity of alpine hydropower facilities, the increased average irradiance of the Alps, and the northerly location of the main load centres (the larger cities).

We also performed simple power flow simulations of this fully renewable Swiss energy system, allowing us to calculate a lower estimate of the storage facilities required to smooth out seasonal variations. The conclusions raise several fundamental questions concerning the optimal infrastructure investments to be made as Switzerland undergoes its energy transition.

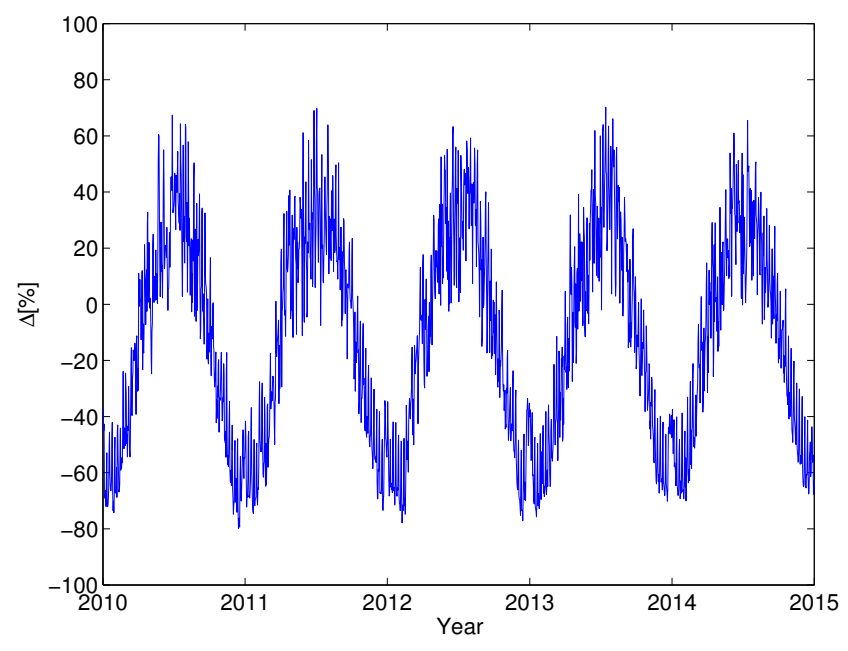

(a)

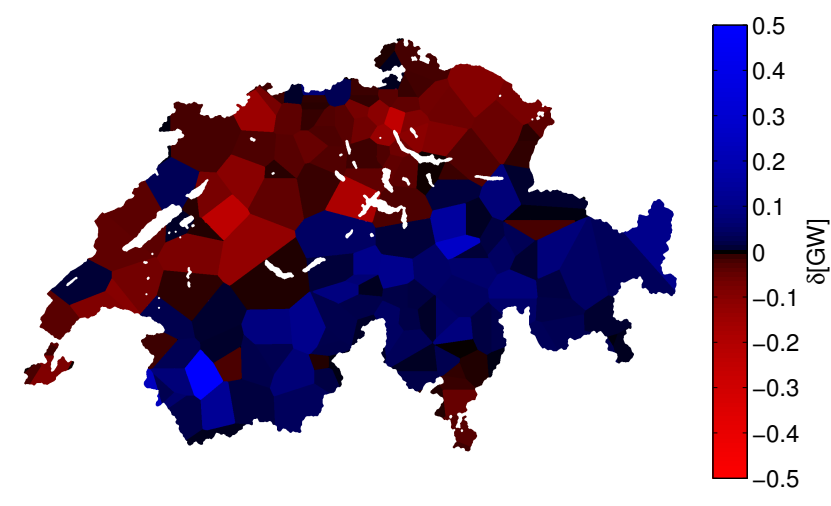

(b)

Figure 1: Mis-match between supply and demand in a fully renewable Swiss power system. a) Spatially averaged (assuming perfect intra-national transmission), temporal mis-match of power. b) Time-averaged, spatial distribution of mis-match. 